\title{
OPEN STANDARDS: A CALL FOR ACTION ${ }^{i}$
}

\author{
Ken Krechmer
}

\author{
University of Colorado
}

\begin{abstract}
Digital communications is both pervasive and vital across society. This creates a growing public interest in the technical standards that proscribe public communications. The public is demanding, "Open Standards." The rallying cry, "Open Standards," means different things to different groups. This paper reviews the different needs of specific groups of society and develops ten different requirements of Open Standards. To implement these requirements, actions by standardization organizations, international bodies (e.g., WIPO, WTO) and national patent office rules are proposed. Interestingly, technical changes, in the form of new standards, rather than legal or policy changes, appear to be the most important mechanism to meet the requirements of open standards.
\end{abstract}

Keywords - open standards, open standardization, open standards requirements, standards successions, standards development organizations

\section{INTRODUCTION}

\begin{abstract}
"Standards function as feathers that guide the arrow of technology. While feathers are light and seemingly trivial on an arrow's shaft, without feathers, few arrows find their mark. Without standards, few technologies find their market" [1].
\end{abstract}

Making technology more responsive to the every expanding needs of the public is always important. Standardization the creation, implementation and use of technical standards, - offers a powerful means for technology to respond to public needs. Technical standards that are more responsive to public needs are often termed open standards. But what does open standards mean? Multiple sources of implementations? No intellectual property costs? Standardized in a formal standardization committee? The standard is the same world-wide? Backward compatibility is maintained? The standard is supported as long as it is used? Open standards mean different things to different people.

Understanding what an open standard is depends on the vantage point of the viewer and the type of technology being standardized. Public standards development organizations (SDOs), private standardization organizations (consortia), different legal communities, economists, software developers, original equipment manufacturers, end users, and governments have quite different views of open standards and how to achieve them.
A technical standard is an established reference. A codified (an independent model or written representation) and quantified (measurable) reference, established by an authority, committee or market (based upon [2]). Based on this definition this paper develops the requirements that bear on the openness of a standard and proposes changes for the policies and procedures of different organizations associated with both the standardization and intellectual property rights (IPR) of standards. As these changes occur, standards will become more open. As this paper indicates, openness is a direction, not a destination which makes technology more responsive to the public's needs.

\section{THE EMERGENCE OF IMPLEMENTERS}

As Standards Development Organizations (SDOs) developed in the late 19th century, they focused, often with government approval, on supporting the open creation of standards and not on the open implementation or open use of standards. At that time the standards committee members represented all aspects of standardization in one organization. As examples, the railroads, utilities and car manufacturers dominated the SDOs and were the major creators and also the implementers and users of standards. The standards creators had no need to separately consider the needs of implementers and users - they were the implementers and users. In the 19th and early 20th centuries, the significant standardization policy issue was the conversion from independent company specifications to single SDO standards [3].

After the middle of the 20th century, large integrated organizations (companies that bring together research and development, production and distribution of their products or services, e.g., IBM, AT\&T, Digital Equipment Corp., British Telecom, France Telecom, NTT) focused on Information Technology standardization. These organizations had engineers who functioned, often on a full time basis, as the integrated organization's standards creators. These standards creators supported specific SDOs necessary for the broad aims of the integrated organization [4].

In the later 20th century, the increase in technology created a need for many more IT standards. Because of the growth of personal computing, cellular telephony and the internet, the number of implementers and users of standards increased dramatically. The stage was set for major changes in standardization activity and processes. By the middle of the 1980s, a new industrial movement emerged where larger integrated organizations began to devolve into segmented organizations where the overall organization exerts the minimum unifying management. Each segment of the overall organization focuses only on its own market(s) and 
therefore only supported the standardization organizations that appeared necessary for their specific product development requirements [5]. This new industrial movement marked the rise of the implementers' activity (independent product development group) in standardization and with it the rise in consortia standardization. At the same time, the overarching integrated organization's standardization organization was disbanded in most cases (e.g., AT\&T, IBM, US PT\&T's BellCore).

Since the 1980s, the technical communications standardization processes have been in transition from being driven by standards creators (standardization participants who are motivated to develop new standards) to being driven by standards implementers (standardization participants who are motivated to produce new products that embody one or more standards). In addition, the users (who usually do not participate in the IT standardization process) have a growing interest in seeing the concept of openness address their requirements. This view is confirmed in the 1994 report sponsored by the US National Science Foundation which described an open data network as being open: "to users, to service providers, to network providers and to change" [6]. Considering service providers and network providers both as examples of implementers (perhaps also creators and users), this report identifies the three major perspectives on open standards: creators, implementers and users.

Product development groups in segmented organizations have no history or allegiance to a specific SDO and choose to support any standardization organization that best fits their product development and marketing needs. Often such a fit is made by sponsoring a new consortium to address the standardization requirements of a developer's product implementation [7]. However, product implementers have very different interests than the standards creators they have replaced. What a product implementer considers an open standard may be quite different from what a standards creator considers an open standard. And they are also different from what a user might consider an open standard.

How many of these indications of an open standard in Table 1 [8] are necessary for a standard to be considered open? Some say standards are open when they do not include controlled intellectual property (e.g., World Wide Web Consortium). Of course, this may be unfair to those who have worked to create useful intellectual property. Some say standards are open when they are standardized in a recognized standardization committee (e.g., formal standardization organizations such as ISO). However, it is now recognized that the difference between formal standardization organizations and consortia is often slight [9]. It appears there is considerable confusion about what an open standard is, as well as how to achieve it.

Open standards are not an idle desire. The search for open standards indicates people's need to influence standards that affect them. Because microprocessor based technology changes rapidly, open standards are needed to respond to such change and yet support public control of new technology. Reviewing the history of standardization shows how standards have been used to control technology for the public good and offers insights into how open standards can be achieved today.
Table 1. Different Views of Open Standards.

\begin{tabular}{|l|l|l|l|l|}
\hline & Rights $\backslash$ Area of Interest & Creator & $\begin{array}{c}\text { Imple- } \\
\text { menter }\end{array}$ & User \\
\hline 1 & Open Meeting & $\mathrm{x}$ & & \\
\hline 2 & Consensus & $\mathrm{x}$ & & \\
\hline 3 & Due Process & $\mathrm{x}$ & & \\
\hline 4 & Open IPR & $\mathrm{x}$ & $\mathrm{x}$ & $\mathrm{x}$ \\
\hline 5 & One World & $\mathrm{x}$ & $\mathrm{x}$ & $\mathrm{x}$ \\
\hline 6 & Open Change & $\mathrm{x}$ & $\mathrm{x}$ & $\mathrm{x}$ \\
\hline 7 & Open Documents & & $\mathrm{x}$ & $\mathrm{x}$ \\
\hline 8 & Open Interface & & $\mathrm{x}$ & $\mathrm{x}$ \\
\hline 9 & Open Access & & $\mathrm{x}$ & $\mathrm{x}$ \\
\hline 10 & On-going Support & & & $\mathrm{x}$ \\
\hline
\end{tabular}

\section{THE SUCCESSIONS OF STANDARDS}

Over the course of history, different standards have supported each wave of civilization (e.g., agrarian, industrial, information). The range of standards required to support a new wave of civilization and the associated technologies is termed a succession of standards [1]. Each succession of standards utilizes different means to balance public and private interests. The succession of standards necessary to support the industrial age are those standards which define the similarity of objects or processes; these are similarity standards. During the industrial revolution, the importance of creating public similarity standards was understood [10]. The use of patents emerged during the same period as a means to offer value to the entrepreneur. Similarity standards created in standardization organizations which supported consensus and due process, when coupled with patents, offered a successful balance of the public and private interests.

In the information age, the standards which define interfaces have emerged as the compatibility standards succession. A fair balance of public and private interests has yet to be achieved here. Compatibility standards began with the development of private interfaces. Such private interfaces were controlled by patents or proprietary information. Patents on interfaces have a winner-take-all effect, assuring a very large private gain to the innovator who controls a high volume interface. Many have recognized the need for open standards of high volume interfaces. But creating open standards for such interfaces is more difficult than creating open similarity standards.

The open creation, open implementation and open use of compatibility standards is necessary to create pubic interfaces. To achieve a better balance of the public value of an open standard with the private gain possible on interfaces defined by compatibility standards, changes are needed including:

- New patent examination procedures (e.g., higher requirements for claims bearing on interfaces) 
- New patent policies (e.g., no patents on adaptability mechanisms, shorter patent periods for claims on algorithms)

- New standardization organization procedures (e.g., only allow intellectual property rights on interface options, evaluate costs of IPR versus performance gain)

- Adaptability mechanisms

A better balance of public and private interests on compatibility standards also requires recognition that similarity and compatibility standards have very different impacts on society. Organizations that deal with both successions of standards need to have different approaches and policies to address similarity and compatibility standards. A fundamental issue is that compatibility standards define interfaces. Communications interfaces created in standardization committees are mutual agreements, not inventions, therefore the intellectual property claims on the implementations of compatibility standards that define interfaces should be minimized.

In the post-information age a new succession of standards has emerged. When interfaces are computer controlled, they can adapt to different requirements. The standards that define how to identify, negotiate and select among different interface requirements are termed adaptability standards. Developing and using adaptability standards offers new means to achieve a successful balance of public and private interests for compatibility standards.

Where algorithms controlled by IPR are desired to optimize the performance of interfaces, such algorithms could be optional, thereby rendering the interface more open. Adaptability mechanisms allow the selection of such options. Standardization organizations should only standardize controlled interfaces where it is clear that the public good, increased performance of the interface using controlled technology, is greater than the private gain desired by the owners of the controlled technology. The market is the best means to determine if a controlled (via IPR) performance enhancement of an interface provides sufficient value given its cost. Market determination, a basic means to support open interfaces, can only function if the controlled technology is optional in any interface standard.

\section{THE TEN REQUIREMENTS OF OPEN STANDARDS}

The 10 requirements described in Table 1 are fundamental to the broadest concept of open standards. Placing each requirement in context helps explain the requirements and identify where different policies and procedures to support each requirement are needed.

1 Openness - all stake holders may participate in the standardization process.

2 Consensus - all interests are discussed and agreement found, no domination.

3 Due Process - balloting and an appeals process may be used to find resolution.

These three requirements of open standards are related to the creation of standards. In the early 20th century, these requirements emerged to prevent exploitation of the standardization process by dominant organizations or factions. This was very important during the period when there was often a dominant railroad, car company, telephone company, etc. in each major country of the world. As trade has expanded, the market dominance of such companies has declined, helped in part by active anti-trust concerns. The participants of standardization meetings are also more aware of these issues now and more able to counter attempts by one faction to dominate a standardization process.

4 One World - same standard for the same function, world-wide.

The first four requirements of open standards are at the heart of the World Trade Organization (WTO) Agreement on Technical Barriers to Trade, Code of Good Practice (http://www.wto.org/english/tratop e/tbt e/tbtagr e.htm\#A nnex $\% 203$ ). The fourth requirement, the same standard for the same function world-wide, is an important requirement to prevent technical barriers to trade (TBT). Yet, many interface standardization committees create standards for a specific geographic area (e.g., ATIS [USA], ETSI [Europe], TTC [Japan]). The creation of compatibility standards by country or region does not make common world-wide communications easier. One way to address this dichotomy of national and regional standardization organizations and the need for communications world-wide is to utilize adaptability standards to negotiate among multi-mode devices supporting multiple national or regional compatibility standards.

Common world-wide adaptability standards need to be developed in international standardization organizations and should be required wherever two or more compatibility standards compete to define the same microprocessor controlled interface. This should be a new WTO requirement under the TBT requirements. Such a requirement would allow national standards, such as China and the USA both desire, yet support the adaptability necessary to use a common communications interface.

5 Open IPR - low or no charge for IPR necessary to implement the basic standard. IPR is allowed for options and proprietary extensions.

The existing procedures for addressing IPR issues in standardization organizations were created to deal with IPR relating to similarity standards; they do not work well for IPR relating to compatibility or adaptability standards. The IPR relating to similarity standards and the IPR relating to compatibility standards have very different economic impacts. The existing reasonable and non discriminatory (RAND) rules of standardization organizations for IPR are appropriate for IPR on similarity standards yet are often ineffectual for IPR relating to compatibility standards. It seems likely that IPR should not be allowed on adaptability standards.

As an example, a cell phone implementer invents and patents a new battery that provides more use per charge. The IPR relates to the chemistry of each battery. If the new battery performance was standardized (as minimum usage time per charge), the standard would be termed a similarity standard. If another inventor created a different battery chemistry that provided as much usage per charge, that battery would meet the requirements of the standard also. With similarity standards that define minimum performance each user can decide if the additional costs for longer battery life is warranted relative to its cost. Properly 
written similarity standards offer both the implementer and user flexibility in their choice of new technology.

The case with compatibility standards that define interfaces is quite different. If the cell phone implementer holds IPR on the compatibility standard that defines the air interface of the cell phone system, all who wish to use of that cell phone system must pay for that IPR without any decision on their part about the value of that IPR to them. Using patents to control compatibility is effectively an expansion in the applicability of the patent system that impacts the rights of others. This unplanned expansion of the patent system needs to be recognized and addressed.

Standardization committees should require an adaptability mechanism whenever multi-mode operation to support proprietary features is desired. When proprietary features included in an interface standard are optional, the implementers of the equipment on each side of the interface standard (e.g., cell phone and cellular base station) will have to choose if an option is worth including in their implementations. This gives the implementers a practical negotiating position for specific IPR. Conversely, if a controlled option significantly improves the system's performance, any implementers that did not choose to include that option in their implementations would run the risk of not being competitive with implementers that did include the option. In this manner a market based negotiation between implementers and IPR holders is supported by requiring proprietary features controlled by IPR in compatibility standards to be optional and negotiable.

Far too often each participant in the standardization process accepts others' IPR into a new interface standard if their IPR is also accepted into the standard. This serves to ensure that the key participants in the interface standardization process gain a part of the royalties that may accrue. While this allows consensus to be achieved, it is not fair to those who have not participated in the standardization process. It is also unfair to users who will ultimately bear the cost of the IPR, often without any input in determining if the IPR included in a standard is desirable to them. It is the high tech equivalent of taxation without representation.

National courts, governments and many international organizations do not appear to be fully aware of the impact of an interface standardization process. The conversion of public telephone utility companies (PT\&Ts) to private companies offers one example. When PT\&Ts have submitted controlled technology to standardization committees for inclusion in an interface standard, it was usually with the assumption (sometimes stated) that no royalties would be charged because they were a public utility. Where patented technology of the PT\&T is already included in public compatibility standards, the future value of that patented technology is assured. Currently when a PT\&T patent portfolio is transferred to a private company, the private company receives a windfall (increased private gain from the future patent royalties). In effect, it is a transfer of value previously in the public domain to private enterprise. In 1996, a significant portion of the AT\&T Bell Labs patent portfolio was transferred to its private successor, Lucent. After this transfer, Lucent began charging for patents that had previously not been enforced
[11]. The open use of AT\&T's patents included in existing public compatibility standards was an issue which should have been considered in the transfer of these patent rights from AT\&T, formally a public utility, to Lucent, a private company.

When multiple companies in an industry gather together to support a specific technology to be standardized, this can be an indication of market dynamics working or it can be an indication of a collusion which prevents other useful technologies from being considered. Where there is controlled IPR and active cross licensing, standardization of the controlled technology may become a means to prevent others (without a cross license) from competing. The current government policies do not control such practices.

Many of these problems can be minimized by a policy change in the standardization organizations. All controlled IPR should be optional in compatibility standards (see "8. Open Interfaces," below), and prevented in adaptability standards. When controlled IPR emerges after the standard is issued, the standard should be changed to make such IPR optional. When compatibility standards can be automatically upgraded over the Internet, making such changes in the standard after it is issued is practical.

\section{Open Documents - all may access and use committee documents, drafts and completed standards for their intended purpose.}

Committee documents, completed standards and software documentation should be readily available. This requirement allows any interested party to be able to see any documents that relate to a standard. In practice the openness of a standardization meeting is closely related to the availability of the documents from the meeting. All technical documentation falls into two classes: work-inprogress documents (e.g., individual technical proposals, meeting reports), and completed documents (e.g., standards, test procedures). Different interest groups need access to these different classes of documents. Standards implementers and software developers need access to workin-progress documents, to understand specific technical decisions, as well as access to completed standards. Implementation testers (including users and their surrogates) also need access to completed documents.

The Internet Society (ISOC) supports an internal standards making organization, the Internet Engineering Task Force (IETF). The IETF has pioneered new standards development and distribution procedures based on the Internet. While the IETF does not meet the openness requirements for Consensus and Due Process, the IETF is perhaps the most transparent standardization organization. Using the Internet, the IETF makes available on the web both its standards, termed RFCs, and the drafts of such standards at no charge. Using the facilities of the Internet, IETF committee discussion and individual technical proposals related to the development of standards can be monitored by anyone and response offered. This transparent development of IETF standards has been successful enough that many other standardization organizations are now doing something similar.

Ultimately, as technology use expands, everyone has an interest in technology and the technical documents that describe it. Using the Internet, access to documents and discussion may be opened to all. In this way, informed 
choices may be made about being involved in a specific committee or project, and potential new participants could evaluate their desires to participate. Open Documents deserves to be a requirement for any standardization organization that wishes to be considered open.

7. Open Change - all changes are proposed and agreed in the standardization organization.

To maintain openness, all changes to existing standards need to be presented and agreed in a standardization organization supporting the previous six requirements of open standards (identified above). Controlling changes is a powerful tool to control interfaces when system updates are distributed over the Internet and stored in computer memory. Even with the most liberal of IPR policies, Microsoft would still be able to control its Windows Application Programming Interfaces (APIs) by distributing updates (changes) to users that update both sides of each API at the same time. Competing vendors' products on one side of the same API, without a similar update at the same time, would be rendered incompatible by such a Microsoft online update. Users recognize the potential of Microsoft updates to cause incompatibilities in nonMicrosoft software systems and often avoid using nonMicrosoft software in Microsoft environments.

The only way that interfaces can remain open is when all changes are presented, evaluated and approved with a common distribution plan in a standardization committee that supports the first six requirements identified above. Considering how computers are connected over the Internet, identifying and requiring mutually agreed changes is vital to the concept of open standards.

This is not widely understood. The original US judicial order to breakup the Microsoft PC-OS and application software monopoly did not address this key issue [12]. On March 24, 2004, the European Commission (EC) announced its decision to require Microsoft to provide their browser (Explorer) independently of the Windows operating system and make the related Windows APIs available to others [13]. This decision also did not address the necessity for mutually agreed change.

"On 10 November 2005, following input from the European Commission's technical advisers (OTR) and an extensive market test, the Commission issued a Decision pursuant to Article 24(1) of Regulation 1/2003 ('the Article 24(1) Decision'). This decision concluded that Microsoft was not complying with its obligation pursuant to the Decision to: (i) supply complete and accurate interoperability information; and (ii) make that information available on reasonable terms" [14].

Unfortunately this decision also does not address the need for mutually agreed changes to maintain "accurate interoperability information." It appears that neither the US judiciary nor the EC OTR understands that a computer controlled interface cannot be mandated to be an open standard. For such a standard to be open, it must be created and maintained in an open standardization process. As currently conceived, the EU approach to opening Microsoft's server interfaces will fail. Microsoft's competitors are likely to recognize that they cannot maintain sufficient control of the EC-created Microsoft server interface to assure their customers of continuing compatibility.
8. Open Interfaces - support migration (backward compatibility) and allow proprietary advantage, but standardized interfaces are not hidden or controlled.

The user's economic interests are best served when manufacturers or service providers compete. Without competition a seller becomes dominant and the user's interests, economic and otherwise, are often not addressed. Standards represent a means to help balance the buyers' and sellers' interests, but when everything about a transaction is standardized there is no longer any product competition, only price competition. While price competition is desirable, the manufacturer or service provider also needs to have the possibility of feature competition to motivate innovation. In similarity standards, a balance can be achieved by standardizing some aspects of a product or service but allowing others to be proprietary. For example, a brick's size may be standardized, but color, texture or strength can be proprietary features. Compatibility (interface) standards also require a balance to offer the greatest value to society. Unfortunately, many people think that all interfaces of a specific type must be the same to ensure compatibility. This is not correct. Interfaces can be made adaptable to support proprietary advantage (private gain) as well as compatible operation (public good).

Interfaces that are not hidden or controlled and which support migration, can also support proprietary advantage. Such interfaces, which exhibit both proprietary and public advantages, are an emerging approach to interface standards used between programmable systems. Programmable systems with changeable memory make possible multimode interfaces that can be changed to support backward and forward compatibility as well as compatibility to other modes of operation. The idea that Open Interfaces should embody both public and private advantage is relatively new. But interest is increasing due to the considerable success of open interfaces in facsimile (T.30), telephone modems (V.8 and V.32 auto baud procedures) and Digital Subscriber Line transceivers (G.994.1 handshaking).

One way of achieving open interfaces is to implement a newer technique called an etiquette [15]. Etiquettes provide:

- Connectivity, negotiating between two or more devices in different spatial locations to determine compatible protocols.

- A means to allow both proprietary and public enhancements to the interface that do not impact backward or forward compatibility.

- Adaptability, so that one communications system can become compatible with a different communications system (e.g., by uploading the needed software).

- Easier system troubleshooting by identifying specific incompatibilities.

As long as the etiquette itself is common between the equipment at both ends, it is possible to receive the code identifying each protocol supported by the equipment at a remote site. Checking this code against a data base of such codes on the web or in a manual, the user can automatically or manually select compatible operation or determine what change is necessary in their system or the remote system to enable compatibility.

One of the earliest etiquettes is ITU Recommendation T.30 which is used in all Group 3 facsimile machines. Part of its function includes mechanisms to interoperate with 
previous Group 2 facsimile machines while allowing new features (public as well as proprietary) to be added to the system without the possibility of losing backward compatibility. Another etiquette is the ITU standard V.8 which is used to select among the V.34 and higher modem modulations. More recently ITU G.994.1 provides a similar function in Digital Subscriber Line (DSL) equipment.

As an example of the usefulness of Open Interfaces, consider Microsoft APIs. Assume that an open standard based upon a Microsoft Windows API is created. Then any vendor could create an operating system (OS) to work with Microsoft's applications or create applications to work with Microsoft's OS that utilize that API. If any vendor (including Microsoft) identified a new function such as a music delivery service or IPTV that was not supported across the standardized API, that vendor could then offer the new function, as an identified proprietary feature across the API, to users who have purchased that vendor's OS and appropriate applications, while not impacting compatibility for those who have not. Since an Open Interface supports proprietary extensions, each vendor controls the way the new function is accessed across the API, but does not change the basic compatibility of the API. In this manner any implementer - including Microsoft - is able to maintain control and add value, based on the desirability of the new functions they offer.

An Open Interface offers a means to address current political concerns:

- The French government's concern that only Apple iPods can download music from Apple iTunes web sites.

- The Chinese government's push for their own communications technology in Chinese communications systems [16].

- The European Union and previous US anti-trust actions over Microsoft's proprietary software interfaces [12].

In each of these cases, Open Interfaces which support adaptable operation could resolve the political concerns without any direct government involvement in standardization. [17] notes that government action mandating a specific standard tends to produce poor results.

9. Open Access - objective conformance mechanisms for implementation testing and user evaluation.

Implementation assessment covers all possible parameters that may need to be identified as conforming for accurate, safe and/or proper use. Such parameters could include physical access (e.g., access by people with disabilities), safety (e.g., CE or UL mark, the European and US indications that equipment is designed safely) and correct weights and measures (e.g., certification of scales and gasoline pumps) as well as interface compatibility indicated by noting a term that indicates the type of interface (e.g., V.92, WiFi, Bluetooth, GSM). Implementation assessment may be as simple as identifying a known brand or it may require specific testing by implementers, regulators, users or their testing agencies. Conformance may be displayed by a known and controlled identification mark (e.g., UL, $\mathrm{CE}$ ) or just a specification calling out existing standards.

For products that conform to similarity standards, a simple mark of conformity is often sufficient. In the European Union (EU), the CE marking is the manufacturer's indication that the product meets the essential (mostly safety) requirements of all relevant EU Directives. This specific marking indicating compliance reduces the user's safety concerns. For products that have standardized interfaces, such as communications equipment or communications software, an interoperability event may be needed (often termed a plug-fest) to test whether different implementations interoperate.

The complexity of multi-layer communications products makes compatibility more difficult to achieve, let alone identify. More complex compatibility standards would benefit greatly from adaptability mechanisms (as discussed under 8 Open Interfaces). These adaptability mechanisms could help achieve the highest level of compatibility. The same mechanisms could identify incompatibility in a manner that would allow upgrades (automatic or manual) to achieve compatibility. Adaptability standards require new levels of testing to verify their long term ability to maintain backward compatibility. While all other implementations are tested to verify conformance to a standard, implementations of adaptability standards also need to be tested to verify that they ignore what they do not recognize, that is, any extensions to the standard that occur in the future. This level of testing is rarely being done currently; it represents new criteria for conformance testing for organizations concerned with the conformance of implementations supporting adaptability standards.

\section{On-going Support - standards are supported until user interest ceases.}

Users desire their products, services and the related software to be supported until their interest ceases, rather than when implementer interest declines. On-going support of hardware, software and services, and their associated standards, is of specific interest to end users as it may increase the life of their capital investment in equipment or software. The support of an existing standard, which directly impacts any products that utilize the standard, consists of five distinct phases (Table 2).

It is difficult to interest users in the first phase of standards development [18]. Even the second phase, fixes, may be of more interest to the creators and implementers than the users. The next three phases, however, are where users have an interest in maintaining their investment. Currently few standardization organizations actively address maintaining their standards based on user desires. Greater user involvement in the on-going support of standards would be practical by taking advantage of the Internet to notify users of potential changes in specific standards. Increasing the users' involvement with the maintenance phases of the standardization process may also represent new economic opportunities for standardization organizations. For example, users could, for a small fee, register on the Internet their interest in a standard or group of standards; then whenever a new support phase of those standards was being considered, the users would be notified and could raise any concerns. Much like any concerns raised in the standardization process, the users' concerns could be addressed as part of evaluating the desirability of the change. Over time, such treatment might also increase the users' preference for standards from the standardization committees which provide such policies. 
Table 2. Standards life cycle.

\begin{tabular}{|l|l|l|l|}
\hline Phase & Activity & Description & $\begin{array}{l}\text { Major Interest } \\
\text { Group }\end{array}$ \\
\hline 1. & $\begin{array}{l}\text { Create } \\
\text { standard }\end{array}$ & $\begin{array}{l}\text { The major task } \\
\text { of SSOs }\end{array}$ & creators \\
\hline 2. & $\begin{array}{l}\text { Fixes } \\
\text { (changes) }\end{array}$ & $\begin{array}{l}\text { Rectify problems } \\
\text { identified in } \\
\text { initial } \\
\text { implementations }\end{array}$ & implementers \\
\hline 3. & $\begin{array}{l}\text { Maintenance } \\
\text { (changes) }\end{array}$ & $\begin{array}{l}\text { Add new features } \\
\text { and keep the } \\
\text { standard up to } \\
\text { date with related } \\
\text { standards work }\end{array}$ & users \\
\hline 4. & $\begin{array}{l}\text { Availability } \\
\text { (no changes) }\end{array}$ & $\begin{array}{l}\text { Continue to } \\
\text { publish, without } \\
\text { continuing } \\
\text { maintenance }\end{array}$ & users \\
\hline 5. & Rescission & $\begin{array}{l}\text { Removal of the } \\
\text { published } \\
\text { standard from } \\
\text { distribution }\end{array}$ & users \\
\hline
\end{tabular}

The ITU-T Telecommunications Standardization Bureau Director's Ad Hoc IPR Group report, released in May 2005, includes "On-going support-maintained and supported over a long period of time" as one element of its Open Standards definition (http://www.itu.int/ITU-T/othergroups/ipradhoc/openstandards.html). The recognition is increasing that on-going support is a part of open standards.

\section{POLICY AND PROCEDURE RECOMMENDATIONS}

Listed below, in order of importance, are the changes proposed to different organizations' policies and procedures. Changes to standardization organizations:

- Support open interfaces (adaptability standards) as a requirement with all compatibility standards using microprocessor controlled interfaces with changeable software.

- Only allow IPR as an option in compatibility standards. When IPR emerges after standardization, change such controlled functions to options where practical.

- Standardization of adaptability standards to be addressed only in world-wide standardization organizations.

- Each standardization organization should maintain and publish a listing of how they address each of the 10 open standards requirements.

- Offer users the means to participate in the maintenance of the SDOs' standards.

Changes to WTO policies:

- Define as barriers to trade the lack of open change procedures and lack of open interfaces of microprocessor based compatibility standards.

Changes to European Commission competition and antitrust policy:
- When interfaces are required to support competition, empower a standardization organization to create and maintain them.

Changes to WIPO policies:

- WIPO should evaluate the economic basis of IPR claims on international interface standards and make recommendations concerning when controlled technology should be optional in interface standards.

Changes to individual countries' patent policies:

- Require greater demonstration of uniqueness for patent claims that control interfaces.

- Shorter term on patent claims that may control interfaces (e.g., algorithms).

As society becomes more technologically based, technical standards and standardization become more important. Standardization and intellectual property process are always evolving, and because of this flexibility these systems have worked well in the past. This evolution must continue to address the broad changes as standards evolve from similarity to compatibility to adaptability. This necessitates the further evolution of the policies and procedures of all the organizations that are involved.

\section{REFERENCES}

[1] Krechmer, K. "The Entrepreneur and Standards." International Standardization as a Strategic Tool: Commended Papers from the IEC Centenary Challenge, $\mathrm{p}$. 143-154. Geneva: IEC, 2006

[2] Hayek, F. A. Law legislation and liberty. Vol. 1 Rules and order. Chapter 2, Cosmos and taxis. London: Routledge \& Kegan Paul Ltd., 1973.

[3] Brady, R.A. Industrial Standardization, (1929) Chapter I, Historical Setting for the Standardization Movement. New York: National Industrial Conference Board Inc., 1929.

[4] Cargill, C. Information Technology Standardization, p. 113-114. Bedford, MA: Digital Press, 1989.

[5] Updegrove, A. "Consortia and the Role of the Government in Standards Setting." In B. Kahin and J. Abbate (Eds.): Standards Policy for the Information Infrastructure. Cambridge MA: The MIT Press, 1995.

[6] NRENAISSANCE Committee. Computer and Telecommunications Board, National Research Council, Realizing the Information Future. Washington, DC: National Academy Press, 1994.

[7] Updegrove, A. "Best Practices and Standard Setting (How the 'Pros' Do It)." In S. Bolin (Ed.): The Standards Edge, Dynamic Tension. Ann Arbor, MI: Bolin Communications, 2004.

[8] Krechmer, K. "Open Standards Requirements," Journal of Information Technology Standards Research (JITSR), 4(1), 2006.

[9] Egyedi, T. M. "Consortium Problem Redefined: Negotiating 'Democracy' in the Actor Network on Standardization." International Journal of IT Standards and Standardization Research, Vol. 1(2), July-December, 2003. 
[10] Industrial Standardization. P. 11. New York: National Industrial Conference Board, Inc., 1929.

[11] "Lucent. Lucent Technologies announces plans to license intellectual property for high-speed modem technology," 1997. Retrieved from: http://www.alcatellucent.com/wps/portal/!ut/p/kcxml/04_Sj9SPykssy0xP LMnMz0vM0Y_QjzKLd4y3cAsFSYGZzgH6kShiBvGOC JEgfW99X4_83FT9AP2C3NCIckdHRQB02b-

I/delta/base-64 xml/L3dJdyEvd0ZNQUFzQUMvNEIVRS8 2X0FfQkdS?LMSG_CABINET=Docs_and_Resource_Ctr \&LMSG_CONTENT FILE=News_Releases_LU 1997/LU _News_Ārticle_006356\&lu_lang_code $=\mathrm{en}_{-}$WW $\overline{\mathrm{W}}$

[12] Krechmer, K., \& Baskin, E. "The Microsoft anti-trust litigation: the case for standards." Society for Engineering Standards, 2000. Available at http://sesstandards.org/displaycommon.cfm?an=1\&subarticlenbr $=56$

[13] European Union. "EU Commission Concludes Microsoft Investigation, Imposes Conduct Remedies and a Fine." March 24, 2004, 45/04. Delegation of the European Commission to the USA. Retrieved from http://www.eurunion.org/news/press/2004/20040045.ht $\mathrm{m}$

[14] European Union. "The European Commission's Microsoft Case. 2006." Retrieved from http://ec.europa.eu/comm/competition/antitrust/cases/m icrosoft/index.html

[15] Krechmer, K. "The Fundamental Nature of Standards: Technical Perspective." IEEE Communications Magazine, $38(6)$, page $70,2000$.

\section{ENDNOTES}

\footnotetext{
${ }^{\mathrm{i}}$ The ideas presented in this paper have gone through many iterations. This paper is a distillation of Open Standards: Definition and Policy [19]. Open Standards: Definition and Policy in turn considers the policy aspects of ideas from the chapter Open Systems in Digital Convergence [20]. In turn that chapter is an expansion of an earlier Journal of IT Standards and Standardization Research paper [8]. In turn the JITSR paper is a significant revision of a paper published in the Proceedings of HICSS [21]. Finally the HICSS paper is a major expansion of [22].
}

[16] Qu, P. \& Polley, C. "The new standard-bearer." IEEE Spectrum, NA 42(12), pp. 49-52, December, 2005. Available at http://www.spectrum.ieee.org/dec05/2361

[17] David, P. A. "Some new standards for the economics of standardization in the information age." In P. Dasgupta \& P. Stoneman (Eds.), Economic policy and technology performance. Cambridge, England: Cambridge University Press, 1987.

[18] Naemura, K. (1995). "User involvement in the life cycles of information technology and telecommunications standards." In R. Hawkins, R. Mansell and J. Skea (Eds.), Standards, Innovation and Competitiveness. Hants, England: Edward Elgar Publishing Limited, 1995.

[19] Krechmer, K. "Open Standards: Definition and Policy." In L. Denardis (Ed), Opening Standards. Unpublished.

[20] Krechmer, K. "Open Systems in Digital Convergence." In S. Park (Ed.), Strategies and Policies in Digital Convergence, Idea Group Reference, Hershey, PA, USA, 2007.

[21] Krechmer, K. "The Meaning of Open Standards." Proceedings of the 38th Annual Hawaii International Conference on System Sciences (HICSS), R. H. Sprague (Ed.), IEEE Computer Society, Los Alamitos, CA, 2005.

[22] Krechmer, K. "The Principles of Open Standards," Standards Engineering, 50(6), 1998. 